University of Wollongong

Research Online

Faculty of Informatics - Papers (Archive)

Faculty of Engineering and Information

Sciences

June 2006

\title{
Understanding the ERP Investment Decision
}

V. Baker

University of Wollongong, vbaker@uow.edu.au

Follow this and additional works at: https://ro.uow.edu.au/infopapers

Part of the Physical Sciences and Mathematics Commons

\section{Recommended Citation}

Baker, V.: Understanding the ERP Investment Decision 2006.

https://ro.uow.edu.au/infopapers/489

Research Online is the open access institutional repository for the University of Wollongong. For further information contact the UOW Library: research-pubs@uow.edu.au 


\title{
Understanding the ERP Investment Decision
}

\author{
Abstract \\ This paper investigates the multi-million dollar decisions that organizations undertake when they decide \\ to invest in ERP systems. The focus is on the recent decision made by a large manufacturing organization \\ in Australia, to invest in ERP. Many issues surrounding ERP as a source of competitive advantage are \\ brought to light and approaches to solving the complex investment problems are posed. \\ Disciplines \\ Physical Sciences and Mathematics

\section{Publication Details} \\ This paper was originally published as: Baker, V, Understanding the ERP Investment Decision, IEEE 2006 \\ International Conference on Management of Innovation and Technology, Singapore, June 2006, 1, 1-5. \\ Copyright IEEE 2006.
}




\title{
Understanding the ERP Investment Decision
}

\author{
Valerie Baker \\ University of Wollongong, \\ NSW, Australia, 2522.
}

\begin{abstract}
This paper investigates the multi-million dollar decisions that organizations undertake when they decide to invest in ERP systems. The focus is on the recent decision made by a large manufacturing organization in Australia, to invest in ERP. Many issues surrounding ERP as a source of competitive advantage are brought to light and approaches to solving the complex investment problems are posed.
\end{abstract}

\section{INTRODUCTION}

The decision to adopt and implement an Enterprise Resource Planning (ERP) system represents a daunting challenge for any organization. The cost of such systems, runs into the millions, and the success of the investment is hard to predict, as the implementations are often less successful than planned. To date, the literature relating to the adoption of ERP systems focuses on the implementation issues surrounding the project. The result of this research is a host of frameworks and issues to guide managers. However, it is evident that these research solutions do not provide a clear link between investing in ERP and achieving competitive advantage. The current business literature would have us believe that re-engineering business processes around 'best practices' will lead to significant improvements in competitive advantage. The existing models grossly over simplify the problems of the ERP investment decision and firm fit. The purpose of this research is to build on the existing literature to gain empirical insight into whether ERP solutions can provide firms with competitive advantage and whether the existing strategic position and business-unit structures play a role in the success outcomes the organization can expect. This paper will outline the theoretical approach the research will take, and will focus on some issues highlighted by a preliminary case study undertaken with a large Australian manufacturing organization, currently implementing a large scale ERP system. The paper will conclude with an outline of the next steps to be undertaken in the research project.

\section{THE INVESTMENT DECISION AT A LARGE AUSTRALIAN} MANUFACTURING FIRM

An investigation of an ERP investment decision was undertaken to understand the processes that take place when an organization, undertakes a multi-million dollar investment in ERP. Semi-structured interviews were conducted with the decision-making team, which consisted of 10 senior managers. The working party were responsible for defining the business case which would support the investment decision. The organization proceeded with their analysis mid-2004, on the basis that their current ERP system, R2, would be withdrawn from support at the end of 2004. The analysis began with a concept study to investigate whether they would continue using R2 and support themselves, or upgrade to another system and vendor. This led the organization to undertake a review of the packaged ERP products, which existed in the market. The decision to purchase an off-the-shelf package was the result of the prohibitive cost of creating an in-house system. The decision-making team (DMT) undertook an appraisal of what it would cost from a timing and resources perspective, including the costs of hiring consultants, obtaining licenses and the timing of implementation.

The first steps in the decision process were on-site visits to see potential ERP systems in use. The DMT decided they needed to see whether the ERP system could handle the scale of work in their organization. They chose manufacturing companies, which had implemented the systems, to see the size of their manufacturing processes. By doing this, the organization felt that it was minimising the risk of relying on prototype demonstrations by the vendors. Through this process, several packages were immediately struck-off the list, as the team believed they were not scalable.

Before the decision was made to go with the SAP solution, an extensive front-end analysis was completed. This consisted of a feasibility study, where business processes were mapped and a systems design created. The result of this process was a robust estimate for the capital cost of the job.

The DMT decided they wanted to implement a 'vanilla' SAP system. This meant they wanted to implement a standard product, based on 'best practice' solutions. They are confident that this will allow them to benefit, regardless of whether it means that need to change their standard business processes to fit.

During the interviews, the DMT defined the benefits achievable from the ERP system investment. The answers widely varied. The team believed that they would gain operational improvements by standardising their processes and streamlining the business, reducing costs. They also believed that they would gain competitive advantage from the ERP system, even though most of the interview discussion focused on operational improvements and cost-savings, particularly in their plant maintenance. The area where they believed they 
could achieve competitive advantage was in supplier relationship management.

Reflected in the comments made by the DMT was, whilst management felt the ERP investment was a huge risk, and something they had to sink money into, they still wanted longterm benefits. Part of the problem was the intangible nature of the investment, unlike investing in capital plant equipment, such as machinery to paint product. So, whilst it was important for management to know there would be operational improvements, such as improved transaction throughput, they also wanted to strategically leverage the investment, which had cost them millions.

The outcome of the investigation conducted at the manufacturing organization lead the researchers to further explore the key issue of whether ERP is a source of competitive advantage and what the moderating factors may be. The remaining paper, addresses these issues, highlighting the relevant literature and posing the research hypotheses.

\section{IS ERP A SOURCE OF COMPETITIVE ADVANTAGE?}

Much discussion exists around the relationship between investing in ERP and gaining competitive advantage, with academics, vendors and implementing organizations, taking different views. A major selling point of packaged enterprise solutions vendors is the claim that ERP systems will help organizations to achieve competitive advantage. For example, SAP claims that 'PepsicCo joins the growing number of consumer products and food and beverage companies that have adopted SAP solutions to achieve operational excellence and competitive advantages' [1]. Similarly, business consultants, such as Accenture claim that 'ERP solutions help CIOs drive value by extending their enterprise solutions to provide both short-term cost management and long-term competitive positioning'. However, if we listen to Carr [2,3] we know that IT has become a commodity, which means that the act of investing in IT alone, is not likely to lead to competitive advantage gains.

Porter [4] claims that competitive advantage is about differentiating the organization and providing a unique value proposition to its customers. This leads to further argument against ERP as a source of competitive advantage, with some academics arguing that long-term competitiveness may be jeopardised by conventional ERP implementation [5]. ERP systems built on 'best practice' solutions force organizations to change the way they work, to fit with the system. This often leads to conformity in design and functionality across industries [6].

Following Porter's [4] definition of strategy, for an ERP system to provide competitive advantage it must be used in distinctive ways. This means, the result of implementing the system, will change the way employees think about their work, how they feel about their enterprise and the relationships developed within and across organsiation boundaries [5]. If the system allows the organization to develop distinct, tacit knowledge and the ability to change behaviours, as part of the learning process, a competitive advantage may be sustainable [7].

Not only do opinions differ between academics and vendors, on this issue, but also within an organization itself. For example, depending on whose opinion you are seeking in an organization, managers will see ERP playing a role in both operational and strategic improvements. For any organization, working towards a common goal and vision is imperative for success, which means the internal conflict surrounding the benefits achievable by using ERP, could be detrimental to that organization achieving sustainable advantage

\section{THE ROLE OF CONTINGENCY THEORY}

The alignment or fit approach, which has its roots in contingency theory, has long been promoted as the way to get high returns from technology investment [8-11]. The premise of contingency theory is that organisations should take different strategic approaches, given the circumstances they face in their particular industry or market. Contingency theory, provides a normative framework for organizations to follow to increase their levels of performance, by adapting to the environment to remain competitive $[12,13]$. If we take the view that contingency theory suggests, where an advantage comes from a firm's ability to make choices that promote appropriate fit, across strategy, structure, culture and processes [14], a paradox remains when investing in ERP. As LengnickHall and Abdinour-Helm [5] suggest ERP systems fit best within mechanistic, clockwork organizations dominated by routine, highly programmable technologies and operations, yet it would appear that the non-routine learning and change processes found in complex, self-organising systems enable firms to create distinctive competencies from ERP [15].

Hence, if we take the fit approach to determine if, how and when organisation's will achieve competitive advantage from ERP, it appears that the organizational context for which ERP is most suited, in terms of structure, culture and process fit, are exactly the types of organization that will struggle with achieving long-term strategic advantage from ERP. On the other-hand those firms, which have the structure, culture and processes best able to leverage sustainable advantage, present the poorest fit with ERP systems. Moreover, the line defining minimal fit and mist-fit is not obvious [14]. Hence, it is understandable that managers often struggle with the complex choice to invest in IT and how to gain long-term advantages and short-term benefits.

The result of initial organization fit often leads to short-term benefits, but it could be at the detriment of gaining sustainable long-term advantage. This is due to the fact that ERP systems fit best within mechanistic, clockwork organizations dominated by routine, highly programmable technologies and operations, 
yet it is the non-routine learning and change processes found in complex, self-organising systems enable firms to create distinctive competencies from ERP [15].

\section{THE IMPORTANCE OF MANAGERIAL JUDGMENT IN THE INVESTMENT DECISION}

Managers often have to make choices about ERP, relying on something other than the full facts and without a full understanding of the complex environment in which they exist. The executive often has to rely on what Hammond [16] describes as the 'cognitive process of last resort: human judgment'. Priem and Cycyota [17] state that it is the understanding of the judgments made by strategic leaders that is the key ingredient to determine the role of mental processes in strategy development and how these strategies and processes affect firm performance. They equate the process of alignment between IT strategies and business goals with executive judgment.

Judgment and decision-making are important activities that continually engage the attention of academics and practitioners alike. The ability to form good judgments and make wise decisions is considered a successful attribute in almost every society [18]. However, trying to understand and explain decisions made in organizations by both individuals and groups is a complex problem. Part of this problem is due to the unobservable or intangible nature of decision antecedents. The exact nature of these decision determinants varies but evidence suggests that the decision problem is based on the decisionmakers goal and their understanding of the decision problem [19]. Neither of these can be easily observed. What can be observed, however, is the relation between a description of the decision problem and the actual decision or consequences from a decision. These observable actions are based on assumptions about the decision maker's goal or their understanding of the decision problem [16].

The assumption often made is that of rationality. The rational view assumes that the decision maker has a perfect understanding of the decision problem, which allows her to 'select the course of action which leads to [her] goal' [19]. However, the rational assumptions that have underpinned mechanistic approaches to firm strategy and strategic choice have increasingly been questioned for their simplistic assumptions that the world is stable and predictable. Although rational thinking is commonplace this paradigm is suitable only when asked to explain very simple decision problems. The paradigm more often than not, is at odds with observed behavior that is characterized by constantly changing firms and markets.

Decisions that need to be made in dynamic and turbulent environments-as is often the case with ERP investment decisions-cannot be understood under the premise of rationality. When an executive makes a decision about their
ERP strategies it is unlikely that they have a 'perfect' understanding of the decision problem or what the consequences of that decision will be. Decisions are often based on projections of the future and this causes problems as many unforseen events can and do occur between the time a decision is made and the future state when the decision is put into practice. The path dependent nature of technology adoption also means that firms must often make investments based on incomplete information. Investment decisions are made not based on rational returns, but to ensure the firm has in place the strategic options to more fully utilize technology in the future.

A major flaw with the rational paradigm is that it assumes the decision maker's motives can be simply inferred from the consequences of the decisions that are made. However, as Mintzberg's [20] critique of rational planning points out, the 'design school' in strategic management is more fallacy than fact. Not all intended strategies are realized and not all realized strategies are intended. Much anecdotal evidence also indicates that there are good reasons for doubting the usefulness of the rational paradigm in explaining the actual behaviour of people. This means that we need to look for alternative perspectives that may also shed new light on the way manager's deal with complex organizational problems.

One alternative is the judgment paradigm, an important feature of which, is that this approach sees decisions as based on judgment rather than fact [17-19, 21]. It considers the analysis of these judgments as the key to understanding decisionmaking. In complex, real-world problems, the decision maker often has to rely on something other than facts and a full understanding of the decision problem. Instead the decision maker bases their decisions on what Hammond [16] describes as the 'cognitive process of last resort: human judgment'.

Most scholarly efforts have followed the direction of Hambrick and Mason [22] believing that individual knowledge and beliefs can be captured without opening the black box of strategic choice and management cognition. This philosophy stems from the idea that individuals are shaped by their past experience, which in turn reflect external characteristics: attributes which can be used to measure individual choices. The problem becomes the indirect measure of strategic choice. Strategic outcomes are presumed to be due to strategic choice and not other factors like serendipity, communication skills, executive charisma etc [23]. This omission may account in some part, for why practitioners continue to pay little attention to the large amount of published work concerning the antecedents of strategy and ERP performance. This is particularly problematic given the size of business and community investment in scholarly activity. 


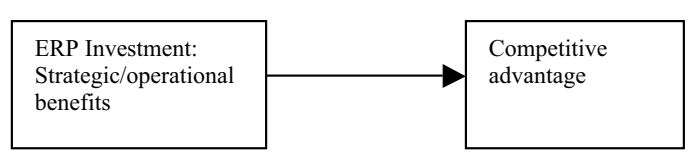

Fig. 1. Model A

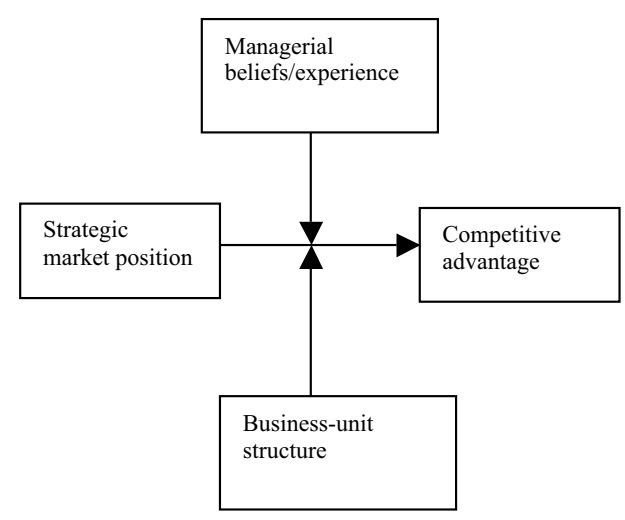

Fig. 2. Model B

\section{V1. RESEARCH FRAMEWORK AND HYPOTHESES}

To overcome the limitations of the existing research, see Model A, Figure 1 (the simplistic model pushed by ERP vendors), we propose Model B, Figure 2, as an underlying framework for tackling this complex problem. If an organization wishes to capture strategic advantage returns from an ERP investment, they need to be in a strong position in the market [4]. However, the relationship between investing in ERP and gaining competitive advantage is complex. For instance, managerial judgement plays an important role in the ERP investment. From research conducted thus far, the beliefs of managers vary, in relation to the perceived benefits from investing in ERP. Capturing these beliefs, plays an important role in understanding why managers invest in ERP and what the outcome of the investment will be. The beliefs managers have about the benefits of ERP fall into two categories, thus we have proposed Hypotheses $1 \mathrm{a}$ and $1 \mathrm{~b}$.

Hypothesis 1a: When the DMT believes operational benefits exist they will invest in ERP.

Hypothesis 1b: When the DMT believes strategic benefits exist they will invest in ERP.

We also know that decision-makers are biased by their background and experience [24]. The beliefs of managers are influenced by their role in the organization and their experiences relating to IT investment.
These experiences impact the beliefs managers have about the perceived benefits of ERP. Hence, Hypotheses $2 a$ and $2 b$ are proposed.

Hypothesis 2a: Negative investment experience is positively related to perceived operational benefits.

Hypothesis 2b: Positive investment experience is positively related to perceived strategic benefits.

Research also suggests that the business-unit structure may play a moderating role in the success outcome of ERP. As contingency theory suggests the fit between business unit structure and long-term versus short-term benefits may differ. We propose that the business-unit structure plays a moderating role in the organization gaining an operational or strategic benefit from the investment, hence Hypotheses $3 a$ and $3 b$.

Hypothesis 3a: Hierarchical business unit structures are associated with higher operational advantages.

Hypothesis 3b: Organic business unit structures are associated with higher strategic advantages

It may be that business-units within the organization will realize different levels of benefits from the investment. This may also relate to why different managers have different beliefs about the ERP investment outcomes. Rather, than merely focusing on the organization level outcomes, we need to focus at the business-unit level, where the system is used. The benefits realized by the business-units will have a major impact on the overall outcome achieved by the organization.

\section{V1I. CONCLUSION}

The likelihood of achieving sustainable competitive advantage from investing in ERP is not as probable as ERP vendors would have organizations believe. The act of investing in a multi-million dollar ERP system is extremely risky for managers. Managers often have to make these investment choices without a full understanding of why they should invest and what the outcome of the investment will be. The perceptions that managers have about the benefits achievable by investing in ERP vary, from tactical and operational to strategic. These mixed perceptions could cause problems for an organization, as there is no overall goal or purpose for investing in such a system. Hence, it is imperative to understand what the perceptions of managers are when they invest in ERP. What is driving the ERP investment? As the previous discussion has outlined intended strategies are not always realized, and we cannot rely on decision outcomes to measure the intent of an original decision. These decisions rely on the judgments that managers make about ERP, based on their role in the organization and past experience investing in Information Technology. 
Thus, the choices managers make, in terms of the beliefs they hold about the investment, need to be measured directly.

Furthermore, if we follow the premise of contingency theory, certain organizations will achieve short-term operational advantages from investing in ERP because their business structures have the best initial 'fit' with IT. However, a paradox remains because down the track it is the hierachical structures, which create 'misfit' with achieving long-term strategic advantage. Hence, another important factor in analyzing ERP as a source of competitive advantage is the role of business-unit structure.

The paper has outlined the problems to answering the question is ERP a source of competitive advantage? An overview of the case study of the ERP investment decision at a large Australian manufacturing organization was presented and several theories, such as judgment theory and contingency theory, have provided the framework for the discussion. Research hypotheses were presented as possible starting points to examining the complex problem, empirically.

\section{References}

1. Seddon, P., Are ERP Systems a Source of Competitive Advantage? Strategic Change, 2005. 14: p. 283-293.

2. Carr, N., IT Doesn't Matter. Harvard Business Review, 2003. 81(5) p. 41-49.

3. Carr, N., Doesn't IT Matter? 2004, Boston, MA.: Harvard Business School Press.

4. Porter, M., Strategy and the Internet. Harvard Business Review, 2001.

5. Lengnick-Hall, C., M. Lengnick-Hall, and S. Abdinour-Helm, The Role of Social and Intellectual Capital in Achieving Competitive Advantage through Enterprise Resource Planning Systems. Journal of Engineering and Technology Management, 2004. 21: p. 307-330.

6. Dillon, C., Stretching Toward Enterprise Flexibility with ERP. APICS - The Performance Advantage, 1999: p. 38-43.

7. Lee, D., M. Hitt, and J. Goldhar, Advanced Manufacturing Technology: Organisational Deisgn and Strategic Flexibility. Organisation Studies, 1996. 17(3): p. 501-523.

8. Henderson, C. and N. Venkatraman, Strategic Alignment: Leveraging Information Technology for Transforming Organizations, in IBM Systems Journal. 1999. p. 472-482.

9. Chan, Y.E., Why Haven't We Mastered Alignment? The Importance of the Informal Organization Structure, in MIS Quarterly Executive. 2002. p. $97-106$

10. Luftman, J., Asssessing Business-IT Alignment Maturity, in Communications of AIS. 2000.

11. Brown, C.V. and S.L. Magill, Reconceptualising the ContextDesign Issue for the Information Systems Function, in Organization Science. 1998. p. 176-194.

12. Duncan, R.B., Characteristics of Organisational Environments and Perceived Environmental Uncertainty, in Administrative Science. 1972. p. 313-327.

13. Dess, G., G.T. Lumpkin, and J.G. Covin, Entrepreneurial Strategy Making and Firm Performance: Tests of Contingency and Cofigurational Models, in Strategic Management Journal. 1997. Miles, R. and C. Snow, Fit, Failure and the Hall of Fame, in Strategy and Organisation: A West Coast Perspective, G. Caroll and D. Vogel, Editors. 1984, Pitman Publishing: Marshfield. p. 1 19.

15. Miller, D., Relating Porter's Business Strategies to Environment and Structure: Analysis and Performance Implications. Academy of Management Review, 1988. 33(2): p. 280-306.

16. Hammond, K., Human Judgment and Social Policy. 1974, Center for Research on Judgment and Policy: Boulder: University of Colarado.

17. Priem and C. Cycyota, On Strategic Judgement, in Handbook of Strategic Management, J. Harrison, Editor. 2000, Blackwell.

18. Arkes, H. and K. Hammond, Judgment and Decision Making: An Interdisicplinary Reader. 1986, Cambridge University Press: Cambridge

19. Brehmer, B., The Role of Judgment in Small Group Conflict and Decision Making, in Judgment and Decision Making: An Interdisciplinary Reader, K. Hammond, Editor. 1986, Cambridge University Press: Cambridge.

20. Mintzberg, H., The Rise and Fall of Strategic Planning. 1994, Prentice Hall.

21. Kaplan, M. and S. Schwartz, Human Judgment and Decision Kaplan, M. and S. Schwartz, Human Judgment and Decision
Processes, in Cognition and Perception, P. Morton, Editor. 1975, Academic Press: London.

22. Hambrick, D.C and P.A. Mason, Upper Echelons: The Organisation as a Reflection of Its Top Managers, in Academy of Management Review. 1984. p. 193-206.

23. Priem and D.A. Harrison, Exploring Strategic Judgment: Methods for Testing the Assumptions of Prescriptive Contingency Theories, in Strategic Management Journal. 1994. p. 311-324.

24. Priem, Executive Judgment, Organizational Congruence, and Firm Performance. Organization Science, 1994. 5(3): p. 421-437. 